University of Nebraska - Lincoln

DigitalCommons@University of Nebraska - Lincoln

Public Health Resources

Public Health Resources

2003

\title{
Chronic Ethanol Consumption Impairs Receptor-Mediated Endocytosis of MAA-Modified Albumin by Liver Endothelial Cells
}

\author{
Michael J. Duryee \\ University of Nebraska Medical Center, 600 South 42nd Street, Omaha, NE \\ Lynell W. Klassen \\ University of Nebraska Medical Center, 600 South 42nd Street, Omaha, NE \\ Thomas L. Freeman \\ University of Nebraska Medical Center, 600 South 42nd Street, Omaha, NE \\ Monte S. Willis \\ Department of Pathology, UT Southwestern, 5323 Harry Hines Blvd., Dallas, TX 75390-9072, USA \\ Dean J. Tuma \\ University of Nebraska Medical Center, 600 South 42nd Street, Omaha, NE \\ See next page for additional authors
}

Follow this and additional works at: https://digitalcommons.unl.edu/publichealthresources

Part of the Public Health Commons

Duryee, Michael J.; Klassen, Lynell W.; Freeman, Thomas L.; Willis, Monte S.; Tuma, Dean J.; and Thiele, Geoffrey M., "Chronic Ethanol Consumption Impairs Receptor-Mediated Endocytosis of MAA-Modified Albumin by Liver Endothelial Cells" (2003). Public Health Resources. 80.

https://digitalcommons.unl.edu/publichealthresources/80

This Article is brought to you for free and open access by the Public Health Resources at DigitalCommons@University of Nebraska - Lincoln. It has been accepted for inclusion in Public Health Resources by an authorized administrator of DigitalCommons@University of Nebraska - Lincoln. 


\section{Authors}

Michael J. Duryee, Lynell W. Klassen, Thomas L. Freeman, Monte S. Willis, Dean J. Tuma, and Geoffrey M. Thiele 


\title{
Chronic ethanol consumption impairs receptor-mediated endocytosis of MAA-modified albumin by liver endothelial cells ${ }^{\text {ts }}$
}

\author{
Michael J. Duryee ${ }^{\mathrm{a}, \mathrm{b}}$, Lynell W. Klassen ${ }^{\mathrm{a}, \mathrm{b}}$, Thomas L. Freeman ${ }^{\mathrm{a}, \mathrm{b}}$, Monte S. Willis ${ }^{\mathrm{c}}$, \\ Dean J. Tuma ${ }^{\mathrm{a}, \mathrm{b}}$, Geoffrey M. Thiele $\mathrm{e}^{\mathrm{a}, \mathrm{b}, \mathrm{d}, *}$ \\ ${ }^{a}$ Department of Internal Medicine, University of Nebraska Medical Center, 600 South 42nd Street, Omaha, NE 68198-3025, USA \\ ${ }^{\mathrm{b}}$ Veterans Administration Alcohol Research Center, Omaha Veterans Administration Medical Center, Research Service 151, Room 321, \\ 4101 Woolworth Avenue, Omaha, NE 68105, USA \\ ${ }^{\mathrm{c}}$ Department of Pathology, UT Southwestern, 5323 Harry Hines Blvd., Dallas, TX 75390-9072, USA \\ ${ }^{\mathrm{d}}$ Department of Pathology and Microbiology, University of Nebraska Medical Center, 600 South 42nd Street, Omaha, NE 68198-6495, USA
}

Received 6 September 2002; accepted 12 May 2003

\begin{abstract}
Alcoholic liver disease has been associated with abnormalities in receptor-mediated endocytosis (RME) which results in abnormal degradation of metabolically altered proteins. Model systems using formaldehyde-modified albumin (f-Alb) have shown an impairment in RME following chronic alcohol consumption utilizing both in situ perfused rat livers and isolated rat liver endothelial cells (LECs). The discovery that alcohol metabolite derived aldehydes can modify proteins prompted a study to determine if malondialdehydeacetaldehyde-modified albumin (MAA-Alb) would be degraded similar to that reported for f-Alb, and whether ethanol-fed rats would demonstrate an impaired RME with respect to this ligand which occurs as a consequence of chronic ethanol consumption.

MAA-Alb was degraded slightly more than f-Alb in both in situ perfused livers and at the single cell level. This degradation was completely inhibited with $100 \times$ unlabeled f-Alb, which suggests the use of a similar receptor. Following alcohol consumption there was a 50-60\% decrease in MAA-Alb degradation in whole livers and isolated LECs. Utilizing isolated LECs it was determined that impairment in internalization was the most likely mechanism for the decrease in the amount of MAA-Alb that was degraded. These data show that chronic alcohol consumption by rats does in fact impair RME of alcohol metabolite-derived adducted proteins, and this impairment is due to a defect in the post-internalization step rather than the binding or degradation of the modified protein.
\end{abstract}

Keywords: Receptor-mediated endocytosis; Aldehyde-modified proteins; Alcohol; Liver endothelial cells; Scavenger receptors; Protein degradation

\section{Introduction}

RME is a process where ligands are bound to a receptor, internalized and shuttled to lysosomal compartments for degradation, and then returned or expelled from the surface

\footnotetext{
is All work was performed at the Veterans Administration Alcohol Research Center, Omaha Veterans Administration Medical Center, 4101 Woolworth Avenue, Omaha, NE 68105, USA.

* Corresponding author. Tel.: +1-402-346-8800x3550; fax: +1-402-449-0604.

E-mail address: LTHIELE@Juno.com (G.M. Thiele).

Abbreviations: f-Alb, formaldehyde-modified albumin; MAA-Alb, malondialdehyde-acetaldehyde-modified albumin; MDA, malondialdehyde; $\mathrm{AA}$, acetaldehyde; RME, receptor-mediated endocytosis; ${ }^{125} \mathrm{I}$, iodine-125; ${ }^{125} \mathrm{I}$-f-Alb, iodine-125-formaldehyde-modified albumin; ${ }^{125} \mathrm{I}$-MAA-Alb, iodine-125-MAA-modified albumin; LECs, liver endothelial cells.
}

of the cell $[1,2]$. Alteration of this process has been linked to a number of diseases, including atherosclerosis, diabetes mellitus, and more recently alcoholic liver disease [3-6]. RME by LECs is an important process in the elimination of chemically modified proteins and altered macromolecules including the following: maleylated albumin, acetylated low density lipoprotein, malondialdehyde low density lipoprotein, formaldehyde treated albumin, and acetaldehyde-modified albumin [7].

Previous studies have shown that chronic ethanol administration alters the ability of LECs to perform RME efficiently. This includes the impaired degradation of both acetaldehyde-modified proteins (AA-Alb) and f-Alb [8,9]. Tuma et al. [5] have shown that MDA and AA bind to proteins to form a hybrid molecule termed the MAA adduct. Antibodies to this molecule have been detected 
in the serum of alcohol-fed rats and human alcoholics $[10,11]$. Taking into account that MAA-modification of proteins at lysine residues is analogous to protein modification by other compounds, we hypothesize that MAAmodification of proteins interferes with RME. Therefore, it was the purpose of this study to determine whether MAAmodified proteins are bound and degraded by in situ perfused rat livers and to utilize isolated LECs to determine which step in the RME process may be altered by chronic ethanol consumption.

\section{Materials and methods}

\subsection{Rats}

Male Wistar rats purchased from Charles River Laboratories were maintained on a Purina rat chow diet, until they reached a weight of 140-150 g, and were divided into three groups. The first group was maintained ad libitum on the standard chow diet for 5-7 weeks to serve as a control group ensuring all results were due to ethanol, and not another dietary factor. The second and third groups were housed individually and acclimated to the Lieber-DeCarli liquid control diet from Dyets, Inc. for 3 days [12]. The rats were paired by weight, one rat was given the ethanolcontaining diet ad libitum, and the other rat was fed an isocaloric amount of the control liquid diet as determined by the pair-fed rat from the day before. Pair feeding was continued for 5-7 weeks. Finally, the ethanol-containing diet consisted of $18 \%$ of the total calories as protein, $35 \%$ as fat, and $36 \%$ as ethanol. In the control diet, ethanol was replaced isocalorically with carbohydrates. All animals were allowed free access to their food and/or water up to $1 \mathrm{hr}$ before sacrifice.

\subsection{Chemicals and proteins}

Bovine serum albumin (Alb) was purchased from CalBiochem. AA was obtained from Aldrich Chemical Co. MDA was obtained as the sodium salt $(\mathrm{MDA} \sim \mathrm{Na}$ ) by treatment of tetramethoxypropane (Aldrich Chemical Co.) with $\mathrm{NaOH}$, according to the method of Kikugawa and Ido [13]. Trichloroacetic acid (TCA), phosphotungstic acid (PTA), formaldehyde, and Percoll were purchased from Sigma Chemical Co. Sodium ${ }^{125}$ I was purchased from Amersham Corporation.

\subsection{Preparation and labeling of ligands}

Alb was labeled with ${ }^{125} \mathrm{I}$ by the chloramine-T method $\left({ }^{125} \mathrm{I}-\mathrm{Alb}\right)$, with resulting specific activities between 2800 and $3200 \mathrm{cpm} / \mathrm{ng}$ [14]. Briefly, proteins were first labeled with ${ }^{125} \mathrm{I}$, and modified with formaldehyde or MAA. Formaldehyde treatment of Alb was done using a modification of the methods of Mego et al. [15] and Horiuchi et al. [16].
As previously described MAA-Alb was prepared by reacting $1.0 \mathrm{mM} \mathrm{AA}$ and $1.0 \mathrm{mM}$ MDA with $2 \mathrm{mg}$ of BSA in $0.1 \mathrm{M}$ phosphate buffer, $\mathrm{pH} 7.2$ at $37^{\circ}$ for 3 days, followed by dialysis against three changes of $0.1 \mathrm{M}$ sodium phosphate buffer for $24 \mathrm{hr}$ at $4^{\circ}$. The percentage of lysines modified by the different aldehydes was determined by the method of Habeeb [21]. Protein concentrations were determined by the method of Lowry et al. [18], and ${ }^{125}$ I-radioactivity was assessed using a Packard Cobra II gamma-spectrometer.

\subsection{In situ liver perfusion}

After 5-7 weeks of liquid diet, rats were anesthetized with Nembutal and perfused as previously described $[9,17]$. Briefly, the liver was equilibrated for $15 \mathrm{~min}$ with oxygenated Krebs-Ringer bicarbonate buffer containing $1 \%$ Alb, followed by a $2 \mathrm{mg} / 200 \mathrm{~mL}$ solution of ${ }^{125} \mathrm{I}-$ modified Alb, MAA-Alb, or f-Alb that was re-circulated for $3 \mathrm{hr}$ through the liver. At various time points, $0.5 \mathrm{~mL}$ aliquots were removed and $2.0 \mathrm{~mL}$ of $20 \%$ TCA and $2 \%$ PTA was added to precipitate intact proteins. Degradation was determined by measuring the amount of acid soluble radioactivity left in the supernatant.

\subsection{Isolation of liver endothelial cells and Kupffer cells $(\mathrm{KCS})$}

LECs and KCs were prepared by perfusion and differential centrifugation methods as described previously [19]. Briefly, livers were flushed with saline containing HEPES to remove red cells, and perfused in situ with $14 \mathrm{mg} /$ $300 \mathrm{~mL}$ of Liberase from CalBiochem for $15 \mathrm{~min}$. The liver was removed, placed in $200 \mathrm{~mL}$ of Dulbecco's phosphate buffered saline (D-PBS) in a sterile $250 \mathrm{~mL}$ flask, and placed on a stir plate with a sterile stir bar for $30 \mathrm{~min}$ at $37^{\circ}$. The suspended cells were filtered through eight plytype VII gauze sponges. Hepatocytes and non-parenchymal cells were separated by differential centrifugation at $100 \mathrm{~g}$ for $5 \mathrm{~min}$ and $350 \mathrm{~g}$ for $10 \mathrm{~min}$ at $4^{\circ}$. Cell pellets were pooled, re-suspended in D-PBS, and centrifuged through a $25 \% / 50 \%$ Percoll gradient at $900 \mathrm{~g}$ for $20 \mathrm{~min}$ at $4^{\circ}$. The LECs and KCs were collected at the interface, washed with D-PBS, and re-suspended in E-STIM ${ }^{\mathrm{TM}}$ media (Cellgro). KCs were isolated by selective adherence to 24 -well plates for $20 \mathrm{~min}$ at $37^{\circ}$, washed and placed in $10 \%$ M199/F12 media. Cells were counted on a hemocytometer and the viability was determined by trypan blue exclusion, and found to be greater than $85 \%$ viable. Cell purity by flow cytometry (data not shown) was found to be greater then $90 \%$ for LECs and KCs using the following antibodies; mouse anti-RECA-1 for endothelial cells (Serotec), mouse anti-ED2 for Kupffer cells (Serotec), mouse anti-desmin for stellate cells (Sigma), rabbit anti-rat ASGP-receptor for hepatocytes (a generous gift from Dr. Carol Casey, VA Medical Center, Omaha, NE) and 
Dil-Ac-LDL for endothelial cells (Biomedica Technologies Inc.).

\subsection{Receptor binding assays}

Receptor number was determined by the specific binding of ${ }^{125} \mathrm{I}-\mathrm{MAA}-\mathrm{Alb}$ to LECs at $0^{\circ}$. Typically, cell suspensions of $1 \times 10^{6}$ cells $/ \mathrm{mL}$ in HBSS containing $1 \% \mathrm{Alb}$ (HBSS-Alb) were incubated for $30 \mathrm{~min}$ at $37^{\circ}$ to increase and equilibrate the number of cell surface receptors. Cells were kept in suspension by use of a metabolic shaker operating at $100 \mathrm{rpm}$. Cell aliquots (typically $1 \mathrm{~mL}$ ) were added to $4 \mathrm{~mL}$ of low $\mathrm{pH}(\mathrm{pH}$ 3.0) cold HBSS-Alb and mixed gently on ice to remove any endogenously surfacebound ligand. Samples were washed in low $\mathrm{pH}$ media by centrifugation at $50 \mathrm{~g}$ for $3 \mathrm{~min}$, the supernatant fluid aspirated, and the cell pellet gently re-suspended in $10 \mathrm{~mL}$ of ice-cold wash medium and re-centrifuged. The washed cells were then re-suspended in $2.0 \mathrm{~mL}$ of cold HBSS-Alb (pH 7.4) and incubated at $0^{\circ}$ for $60 \mathrm{~min}$ with ${ }^{125}$ I-MAA-Alb as described for $\mathrm{f}-\mathrm{Alb}$ by Nilsson and Berg [22]. Following incubation, samples were transferred to tubes containing $2.5 \mathrm{~mL}$ of ice-cold HBSS-Alb, pelleted at $350 \mathrm{~g}$ for $5 \mathrm{~min}$, and washed twice with $2.5 \mathrm{~mL}$ of ice-cold incubation medium. These cell suspensions contained only surface-bound ${ }^{125}$ I-MAA-Alb.

To assess specific binding of the ligand, the cell suspensions were divided into two $5 \mathrm{~mL}$ aliquots ( $\mathrm{pH} \mathrm{7.4);} \mathrm{buffer}$ was added to one aliquot while low pH HBSS-Alb was added to the other. After gentle mixing on ice for $15 \mathrm{~min}$, suspensions were centrifuged, and aliquots $(0.5 \mathrm{~mL})$ of the supernatant fluids were removed to determine free ${ }^{125} \mathrm{I}$ MAA-Alb. Supernatant fluids were aspirated, and the pellets were re-suspended with $5 \mathrm{~mL}$ of HBSS-Alb. Aliquots $(0.5 \mathrm{~mL})$ of the pellet suspension were then removed to determine cell-associated radioactivity. Specific binding was defined as the amount of radioactivity displaced by low $\mathrm{pH}$ treatment of the cells. Low $\mathrm{pH}$ treatment did not affect cell viability or the percentage of single cells. In some cases, specific binding was assessed by including in the binding medium an excess (100-fold) of non-radioactive MAA-Alb. Results of specific binding were similar for both low $\mathrm{pH}$ treated cells and cells incubated with excess unlabeled ligand.

\subsection{Internalization and degradation of ${ }^{125} I-M A A-A l b$ by isolated LECS}

Degradation of labeled MAA-Alb was followed by measuring the amount of acid soluble radioactivity after precipitating intact protein with $20 \%$ TCA/2\% PTA [23]. Briefly, LEC suspensions $\left(1 \times 10^{6}\right.$ cells $\left./ \mathrm{mL}\right)$ were incubated at $37^{\circ}$ for $30 \mathrm{~min}$ in a metabolic shaker to increase and equilibrate the number of cell surface receptors. ${ }^{125} \mathrm{I}-$ MAA-Alb (100 nM, $1500 \mathrm{cpm} / \mathrm{ng}$ of protein) was added, aliquots of the cell suspension $(1 \mathrm{~mL})$ were removed at various time intervals, added to ice-cold centrifuge tubes, and immediately centrifuged to pellet the cells. A $0.25 \mathrm{~mL}$ aliquot of the supernatant was removed and added to $2.0 \mathrm{~mL}$ of $20 \% \mathrm{TCA} / 2 \%$ PTA for determination of acid soluble radioactivity (degradation). After at least $20 \mathrm{~min}$ on ice, the mixtures were centrifuged for $5 \mathrm{~min}$ at $350 \mathrm{~g}$, and radioactivity in the supernatant fluid was determined. At $37^{\circ}$ degradation of ${ }^{125}$ I-MAA-Alb was negligible in the absence of cells.

To determine the internalization of ${ }^{125}$ I-MAA-Alb, pelleted and equilibrated LECs were incubated with ${ }^{125} \mathrm{I}$ MAA-Alb. At various times, LECs were re-suspended and washed twice with $1 \mathrm{~mL}$ of ice-cold HBSS-Alb, and three times with HBSS-Alb at $\mathrm{pH} 3.0$ to remove surface bound ligand. After the low $\mathrm{pH}$ treatment, the cell suspension was centrifuged and the pellet re-suspended in HBSS-Alb. An aliquot of this suspension $(0.25 \mathrm{~mL})$ was added to $2 \mathrm{~mL}$ of $20 \%$ TCA $/ 2 \%$ PTA for determination of internalized ligand. Acid precipitates were washed $20 \%$ TCA $/ 2 \%$ PTA and radioactivity in the precipitated pellet determined. This value represented the amount of intracellular intact ligand. Treatment with low pH HBSS-Alb media and subsequent centrifugation had no effect on cell viability as assessed by exclusion by trypan blue.

\subsection{Statistical analysis}

Statistics were performed using ANOVA analysis comparing the different experimental and control groups. Statistical significance was achieved if $P$ values were less than 0.05 . All statistical analysis was performed using SigmaStat (Jandel, Scientific, 1994).

\section{Results}

\subsection{In-situ degradation of ${ }^{125} I-M A A-A l b$}

Previous studies on the degradation of f-Alb in livers of chow-fed rats showed that $400-500 \mu \mathrm{g}$ of ${ }^{125} \mathrm{I}$-f-Alb was degraded over a $3 \mathrm{hr}$ period of time $[9,17]$. When these same studies were performed in ethanol rats, there was a $40-60 \%$ decrease in $\mathrm{f}-\mathrm{Alb}$ degradation. Knowing that ethanol consumption would impair f-Alb degradation, experiments were performed to determine the effects of ethanol on the degradation of the newly characterized protein-MAA adduct.

As shown in Fig. 1, perfusion of chow-fed or pair-fed rat livers with the MAA adducted Alb (that forms in the presence of $1 \mathrm{mM}$ AA with $1 \mathrm{mM}$ MDA), resulted in the degradation of approximately $450 \mu \mathrm{g}$ of MAA-Alb over a $3 \mathrm{hr}$ time period. This degradation was shown to be decreased by $50-70 \%$ in the livers of rats chronically consuming ethanol in their diet. Additionally, as a positive control a little more than $400 \mu \mathrm{g}$ of f-Alb, which has been used previously by us [17] and others [24-27] as a standard 


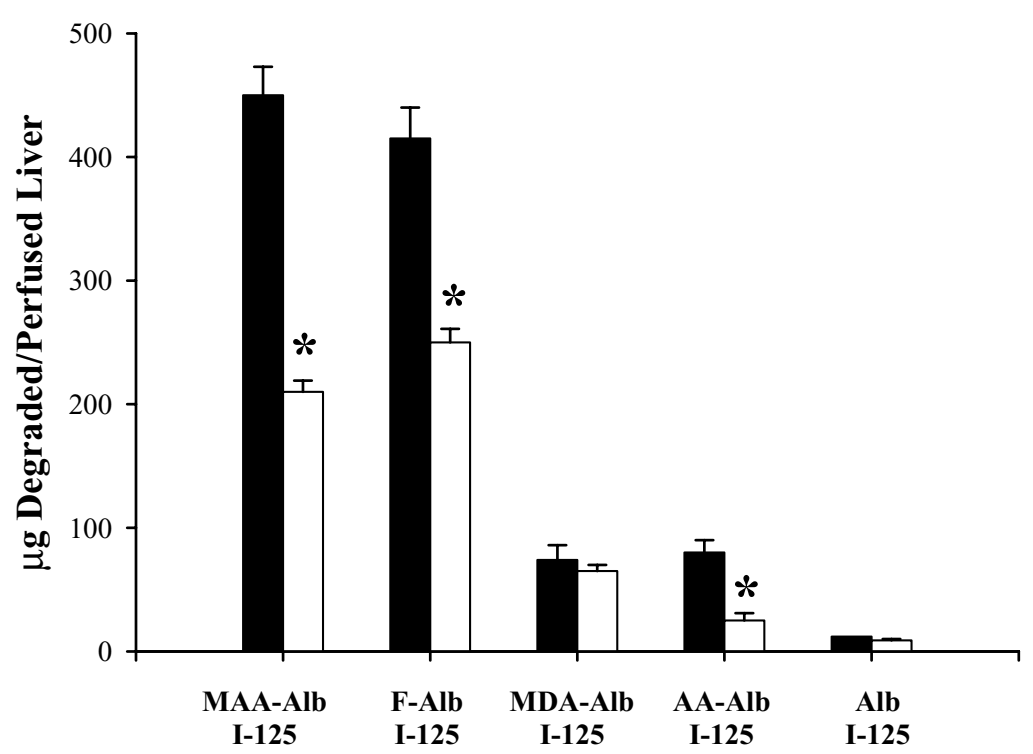

Fig. 1. Degradation of ${ }^{125} \mathrm{I}-\mathrm{MAA}-\mathrm{Alb}$ by in situ perfused livers of chow-fed (filled bars) or ethanol-fed (empty bars) rats perfused with $10 \mu \mathrm{g} / \mathrm{mL}$ of ${ }^{125} \mathrm{I}$ labeled: MAA-Alb, f-Alb, MDA-Alb, AA-Alb, and Alb. These ligands were re-circulated via perfusion for $3 \mathrm{hr}$, aliquots taken, and TCA/PTA precipitated to determine the amount of acid soluble protein (degradation). Experiments were performed using six animals in each group, and significance reported at ${ }^{*} P<0.05$. Animals perfused with ${ }^{125} \mathrm{I}$-MAA-Alb showed significantly higher degradation than those perfused with ${ }^{125} \mathrm{I}$-MDA-Alb, ${ }^{125} \mathrm{I}-\mathrm{AA}-\mathrm{Alb}$, or ${ }^{125} \mathrm{I}$-Alb, but not ${ }^{125} \mathrm{I}$-f-Alb. Additionally, chronic ethanol consumption significantly decreased the amount of degradation of every ligand except for ${ }^{125} \mathrm{I}$-Alb.

ligand of the scavenger receptor, was degraded in the livers of chow-fed rats, with a 40-50\% decrease in this degradation observed in the livers of rats chronically consuming ethanol. Aldehyde control experiments with AA-Alb and MDA-Alb used iodinated Alb that had been exposed to $1 \mathrm{mmol} / \mathrm{L}$ of AA or MDA for 3 days at $37^{\circ}$ and $\mathrm{pH}$ 7.4. As shown in Fig. 1, AA-Alb and MDA-Alb were taken up and degraded by the perfused liver $(75 \mu \mathrm{g})$, at levels that were much lower than those observed with the adduct composed of each of these two aldehydes, MAA-Alb (400-500 $\mu \mathrm{g})$. Interestingly, the exposure of Alb to either of these two aldehydes resulted in products that where $<1 \%$ of the total lysine residues available (Table 1). These data certainly may explain the decreased ability of AA-Alb and MDAAlb to be degraded as compared to MAA-Alb where it was demonstrated that $35.6 \%$ of the lysines were modified.

Table 1

Modification of lysine residues on Alb with different aldehydes

\begin{tabular}{llll}
\hline $\begin{array}{l}\text { Type of } \\
\text { adduct }\end{array}$ & Concentration & $\begin{array}{l}\text { Incubation } \\
\text { time }\end{array}$ & $\begin{array}{l}\text { Percent } \\
\text { modification }\end{array}$ \\
\hline f-Alb & $20 \%$ & $1 \mathrm{hr}$ & 46.7 \\
AA-Alb & $1 \mathrm{mM}$ & 3 days & $<1$ \\
MDA-Alb & $1 \mathrm{mM}$ & 3 days & $<1$ \\
MAA-Alb & $1 \mathrm{mM} \mathrm{AA}+1 \mathrm{mM} \mathrm{MDA}$ & 3 days & 35.6 \\
\hline
\end{tabular}

Note: All adducts were prepared in sealed Eppendorf tubes, wherein $2 \mathrm{mg}$ of ${ }^{125} \mathrm{I}$-BSA was reacted with each concentration of aldehyde in either sodium phosphate buffer $(\mathrm{pH} 7.4)$ or $0.2 \mathrm{~mol} / \mathrm{L}$ carbonate buffer $(\mathrm{pH}$ $10.0)$ at $37^{\circ}$ for their specific incubation time. f-Alb was produced using $20 \%$ formaldehyde. Each product was dialyzed for $16 \mathrm{hr}$ against $0.02 \mathrm{~mol} /$ $\mathrm{L}$ of sodium phosphate buffer containing $0.15 \mathrm{~mol} / \mathrm{L}$ of $\mathrm{NaCl}$ at $4^{\circ}$ with several changes of the buffer. The percentage of modification of lysine residues by the different aldehydes was determined by the method of Habeeb [21]. $P<0.05$.
However, the extent of lysine modification must not be the only factor as f-Alb (46.7\%) is modified much more than MAA-Alb, and is degraded at a slightly but significantly lower level.

To determine whether this degradation was specific for each ligand, the reaction was performed in the presence of a $100 \times$ concentration of unlabeled f-Alb or MAA-Alb. Incubation with $\mathrm{f}-\mathrm{Alb}(100 \times)$ completely inhibited the degradation of either MAA-Alb or f-Alb indicating the receptor(s) responsible for binding and degrading these ligands may be similar (data not shown). Unfortunately, the addition of $100 \times$ MAA-Alb resulted in hepatotoxic effects characterized by dissociation of liver tissue, liver leakage, and rupture. Therefore, the liver did not remain intact and the inhibition of ${ }^{125}$ I-MAA-Alb degradation by unlabeled MAA-Alb was not able to be performed. This has led to other investigations into the effects of MAA-Alb on the liver.

To determine the kinetics of this degradation, rats were fed for 6 weeks on pair, ethanol, and chow diets. Figure 2 shows the degradation of MAA-Alb over a $3 \mathrm{hr}$ period of in situ perfusion. Chow-fed and pair-fed animals degraded approximately $500 \mu \mathrm{g}$ of MAA-Alb, with the ethanol animals degrading only about $200 \mu \mathrm{g}$ of MAA-Alb. The kinetics of this $60 \%$ decrease in MAA-Alb degradation indicated that the degradation of MAA-Alb is impaired in ethanol-fed animals similar to that observed when $\mathrm{f}-\mathrm{Alb}$ was utilized as the ligand in the perfusate [9].

\subsection{Purification and characterization of LECs and KCs}

Previous studies have shown that LECs or KCs are the cells most likely involved in the degradation of these 


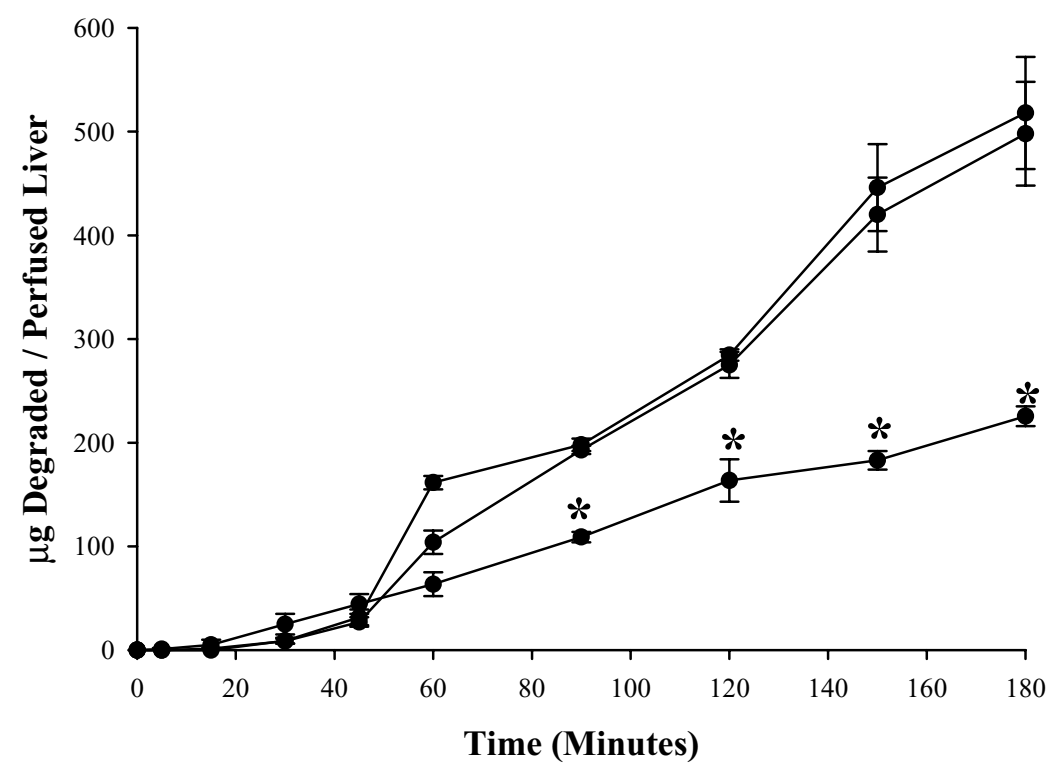

Fig. 2. Effects of ethanol feeding on in situ degradation of ${ }^{125}$ I-MAA-Alb by livers from chow-fed $(\boldsymbol{\square})$, pair-fed $(\mathbf{O})$, and ethanol-fed ( $\left.\mathbf{\Delta}\right)$ rats. Livers were perfused with $10 \mu \mathrm{g} / \mathrm{mL}$ of ${ }^{125} \mathrm{I}$-MAA-Alb, aliquots were taken at indicated times over a $3 \mathrm{hr}$ period and intact protein precipitated with TCA/PTA. Acid soluble radioactivity (protein degradation) in the supernatant was determined. Results are expressed as means $\pm \mathrm{SD}(\mathrm{N}=6$ in each group) and values significantly different from control rats at ${ }^{*} P<0.01$ are indicated.

ligands. Therefore, steps were taken to isolate these cells as described in Section 2. Using a fluorescent activated cell sorter (FACSCalibur), LECs was found to be $>90 \%$ pure by staining with anti-RECA and Dil-Ac-LDL. Staining with anti-ED-2 (Kupffer cell marker) showed that $<5 \%$ of the cells were Kupffer cells, with $<2 \%$ of the cells staining with anti-desmin (stellate cell marker; data not shown). Similarly, KCs were found to be $>90 \%$ pure by staining with anti-ED-2 (Kupffer cell marker). Staining with antiRECA and Dil-Ac-LDL showed $<5 \%$ contamination with LECs, and $<5 \%$ contamination with stellate cells (antidesmin). Finally, the absence of hepatocytes was confirmed by using an antibody to the asialoglycoprotein receptor. The purity of the LECs and KCs did not differ among chow-fed, pair-fed or ethanol-fed rats ( $>90 \%$ pure).

\subsection{Degradation of ${ }^{125}$ I-MAA-Alb by isolated LECS and $K C s$}

To determine the role of LECs in degrading ${ }^{125}$ I-MAAAlb, isolated cell suspensions from chow-fed, pair-fed, and ethanol-fed animals were incubated with $25 \mu \mathrm{g}$ of ${ }^{125} \mathrm{I}$ MAA-Alb, and the amount of degradation determined by counting the acid soluble protein in the supernatant (Fig. 3A and B). As indicated, LECs isolated from chow-fed and pair-fed rat livers degraded $8 \mu \mathrm{g}$ of ${ }^{125} \mathrm{I}$ MAA-Alb $/ 10^{6}$ cells (Fig. $3 \mathrm{~A}$ ). This was about $2 \mu \mathrm{g}$ more than observed for f-Alb [9]. However, the ability of LECs isolated from ethanol-fed animals to degrade the protein was decreased by $50 \%$ resulting in only $3.8 \mu \mathrm{g}$ degraded over the same period of time.

In contrast, KCs demonstrated the degradation of $0.0175 \mu \mathrm{g}$ of ${ }^{125} \mathrm{I}-\mathrm{MAA}-\mathrm{Alb} / 10^{6}$ cells, with no effect of ethanol on this degradation (Fig. 3B). This degradation was approximately 50 -fold less than the amount degraded by a similar number of LECs, and strongly suggests that the major cells involved in the degradation of this ligand are the LECs. Thus, the rest of the studies reported in this manuscript will focus only on LECs.

\subsection{Binding of ${ }^{125} I-M A A-A l b$ to isolated liver endothelial cells}

To compare the binding affinities for ${ }^{125}$ I-MAA-Alb between LECs from chow-fed, pair-fed, and ethanol-fed animals, ${ }^{125}$ I-labeled MAA-Alb was added to cell suspensions as indicated in Section 2. The ability of ${ }^{125}$ I-MAAAlb to bind LECs from chow-fed and pair-fed rats was similar (300 fmol $/ 10^{6}$ cells). As seen in Fig. 4, there was a very small but statistical difference in the binding of MAAAlb to each of the treatment groups, indicating that the abundance of receptor(s) and the affinity for MAA-Alb were slightly different in the presence of ethanol in the diet. However, this difference is not enough to result in a $50-70 \%$ decrease in degradation.

\subsection{Ethanol feeding affects internalization and degradation of ${ }^{125}$ I-MAA-Alb by isolated LECS}

As shown in Fig. 5, ethanol feeding resulted in a $20-40 \%$ decrease in ${ }^{125}$ I-MAA-Alb internalization, which was significantly decreased between 40 and 180 min of incubation. To further determine the role of RME in the observed ethanol-induced defect, LECs were allowed to bind the ligand at $4^{\circ}$ and washed three times with HBSS-Alb. The cells were warmed to $37^{\circ}$, aliquots of the cells harvested, 

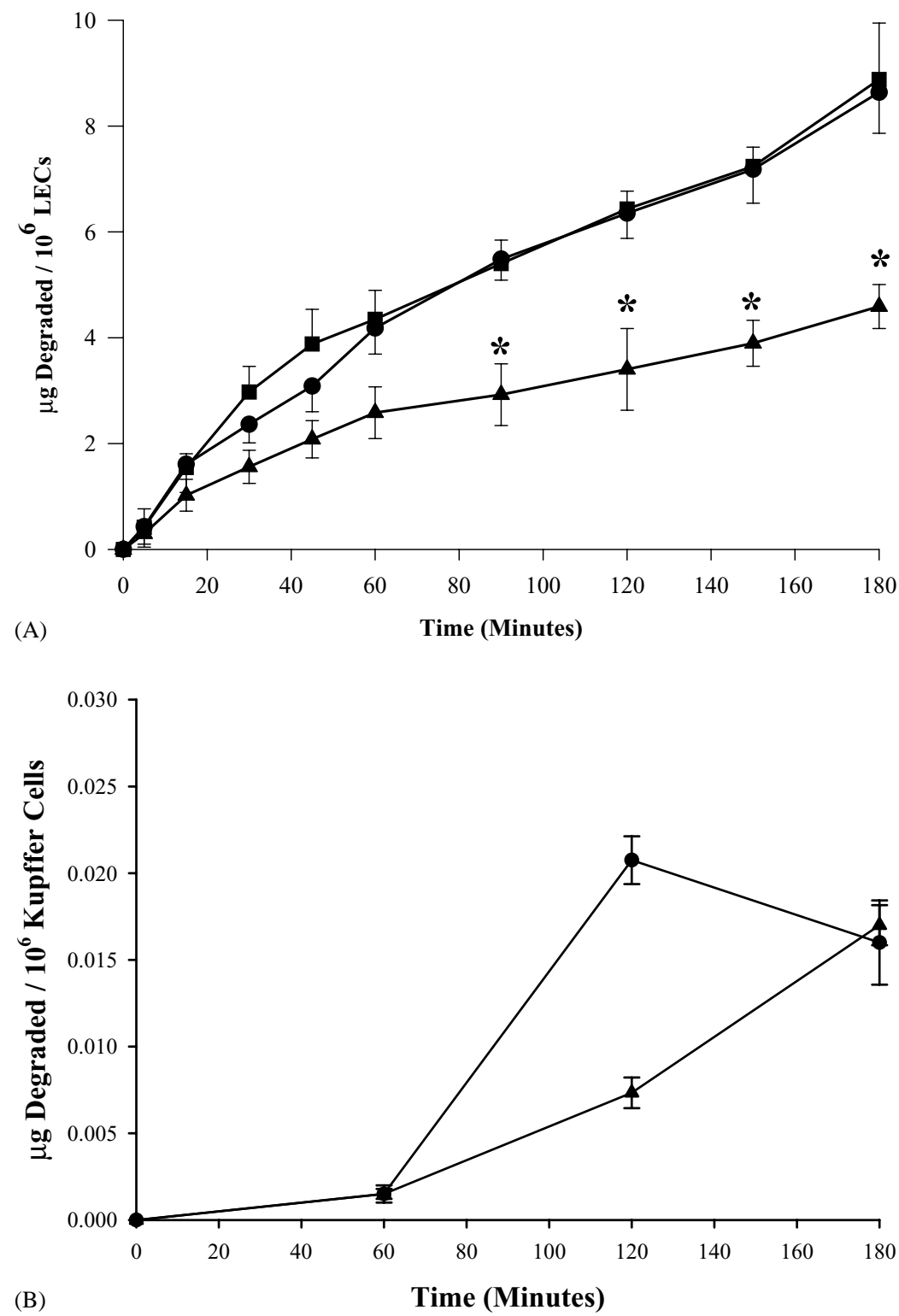

Fig. 3. (A, B) Kinetics of ${ }^{125}$ I-MAA-Alb degradation by isolated LECs (A) and KCs (B) from chow-fed ( $\left.\mathbf{\square}\right)$, pair-fed (O), and ethanol-fed ( $\left.\mathbf{A}\right)$ rats. LEC and $\mathrm{KC}$ suspensions $\left(1 \times 10^{6}\right.$ cells $\left./ \mathrm{mL}\right)$ were incubated at $37^{\circ}$ with ${ }^{125} \mathrm{I}-\mathrm{MAA}-\mathrm{Alb}(25 \mu \mathrm{g} / \mathrm{mL}$ of protein $)$ for the indicated amount of time, aliquots of the cell suspensions $(1 \mathrm{~mL})$ were removed, and acid-soluble radioactivity was determined as described in Section 2 . Results are expressed as means $\pm \mathrm{SD}(\mathrm{N}=6$ in each group), and values significantly different from controls $\left({ }^{*} P<0.01\right)$ rats are indicated.

and the ${ }^{125}$ I-MAA-Alb that was internalized and subsequently degraded was determined. By performing these studies, it was possible to trace ${ }^{125}$ I-MAA-Alb as it traverses into the cell in a single round of binding, internalization, and degradation. As indicated in Fig. 6A, internalization of surface bound ligand was decreased by $50 \%$ in LECs from ethanol-fed animals when compared to cells from the control groups. Additionally, the decrease in surface bound internalization contributed to the decrease in the percent degraded of the total surface bound ligand (Fig. 6B), indicating that the decrease in MAA-Alb degradation resulted from a defect in the internalization of surface bound MAA-Alb. In fact, when the degradation of MAA-Alb was normalized to the amount of surface bound MAA-Alb (Fig. 7), there was no significant statistical difference in the rate of MAA-Alb degradation between the groups supporting the hypothesis that reduced degradation of adducted proteins by LECs from alcoholfed animals results from a defect in internalization of modified proteins and not from a reduced rate of intracellular protein degradation.

\section{Discussion}

LECs have been shown to bind and degrade formaldehyde and acetaldehyde-modified proteins [8,9,17], and chronic ethanol consumption has been shown to result 


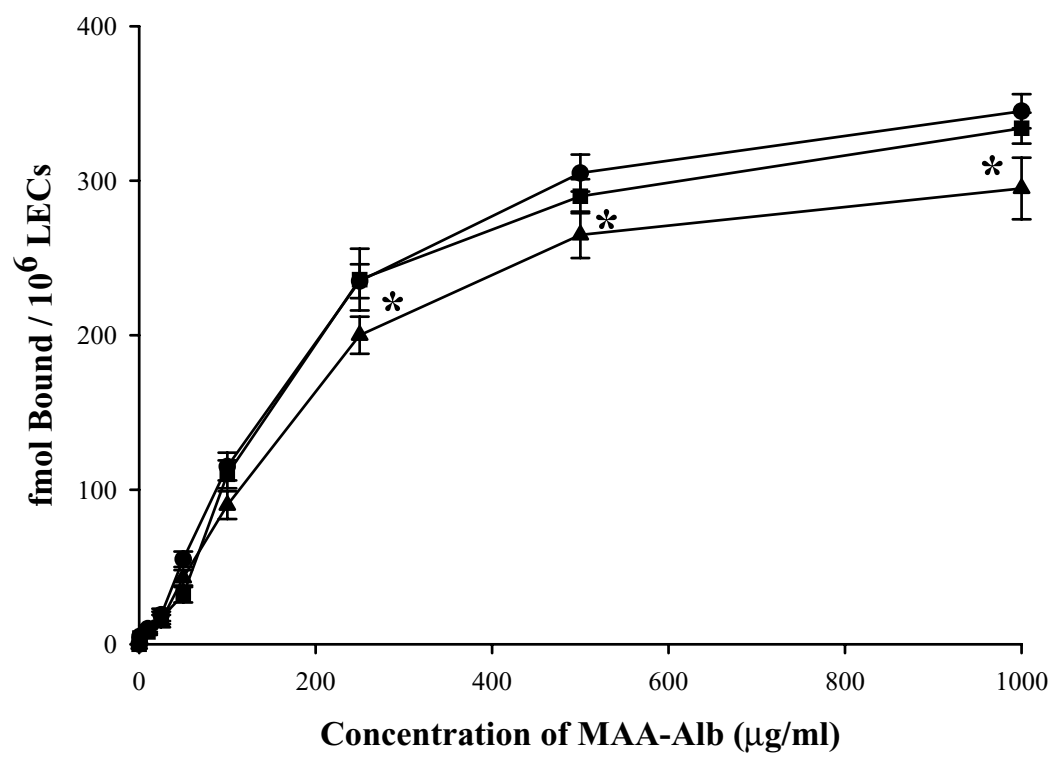

Fig. 4. Binding of ${ }^{125}$ I-MAA-Alb to LECs. Cell suspensions $\left(1 \times 10^{6} / 1.0 \mathrm{~mL}\right.$ in HBSS $)$ were incubated at $37^{\circ}$ for 30 min to increase and stabilize the receptor number, and then chilled on ice. One milliliter of the cold cell suspension was added to tubes containing different concentrations of ${ }^{125} \mathrm{I}$-MAA-Alb (from 1 to $1000 \mu \mathrm{g} / \mathrm{mL}$ ). Total volume was $2.0 \mathrm{~mL}$. The samples were incubated at $0-4^{\circ}$ for $90 \mathrm{~min}$ with constant gentle rotation, diluted with cold HBSS, centrifuged, $0.5 \mathrm{~mL}$ of the supernatant fluid was removed to determine free ${ }^{125} \mathrm{I}-\mathrm{MAA}-\mathrm{Alb}$, and cell pellets were washed once with excess HBSS. Specific binding was determined as described for binding assays in Section 2 and reported as saturation of the binding of ${ }^{125}$ I-MAA-Alb LECs isolated from chow-fed $(\boldsymbol{\square})$, pair-fed $(\mathbf{O})$, and ethanol-fed $(\mathbf{\Delta})$ rats. Specific binding was found to be $76-88 \%$ at all concentrations tested. Results are shown as the means \pm SD for 8 determinations, and significant differences between ethanol-fed and chow- or pair-fed controls reported at ${ }^{*} P<0.05$.

in a significant decrease (50-60\%) in the ability of LECs to degrade these ligands. The f-Alb ligand has been used extensively to characterize LECs as; it is almost exclusively taken up by only this cell type $[3,25,26]$. Additionally, the degradation of f-Alb has been shown to be impaired when LECs were isolated from the livers of rats chronically consuming ethanol, suggesting that the removal of this ligand by RME was affected at the postinternalization step in the process $[8,9]$. However, while formaldehyde-modified proteins are readily degraded by

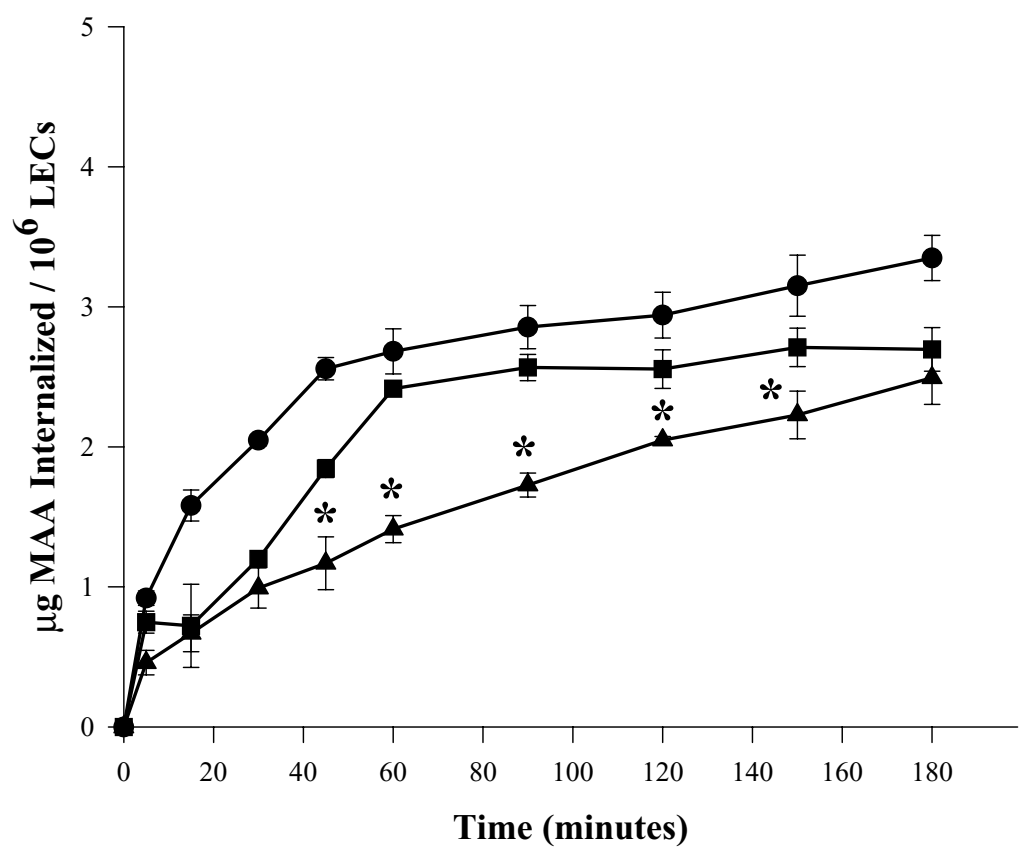

Fig. 5. Kinetics of ${ }^{125}$ I-MAA-Alb internalization by isolated LECs from chow-fed $(\boldsymbol{\square})$, pair-fed $(\boldsymbol{\bullet})$, and ethanol-fed $(\boldsymbol{\Delta})$ rats. Incubation conditions are identical to those listed in Fig. 3. After the cell suspension was centrifuged, the medium was decanted, and the cells incubated in the presence of ice-cold HBSS (pH 3.0) to remove surface-bound ligand. Acid-precipitable radioactivity remaining in the centrifuged cell pellet was then determined as described in Section 2. The amount of internalized ligand was expressed as the mean \pm SD for 6-8 determinations. Values were considered significantly different at ${ }^{*} P<0.01$. 


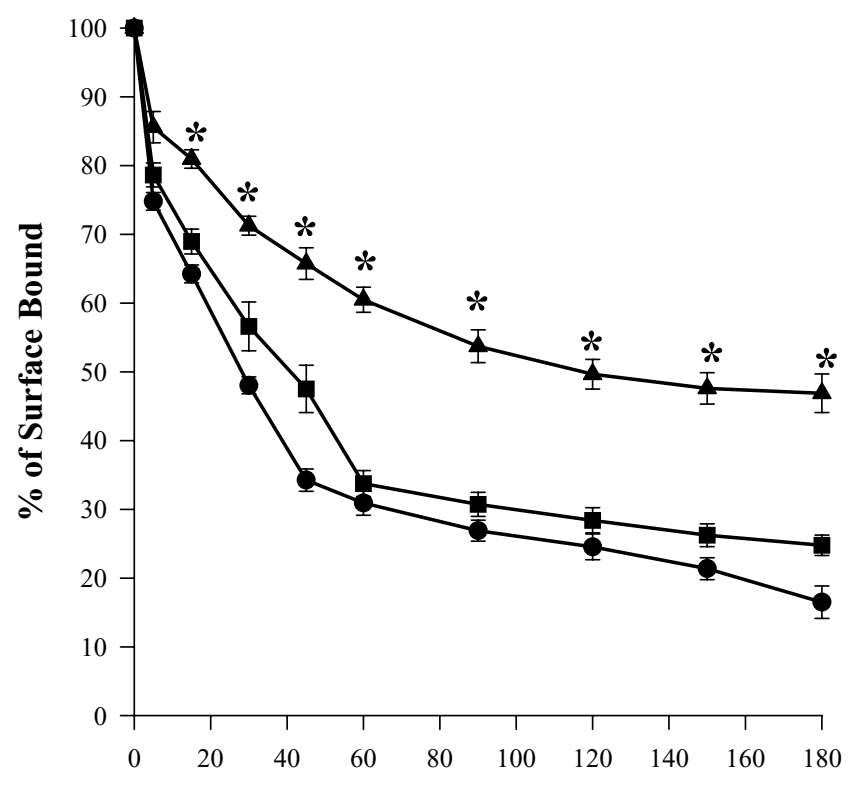

(A)

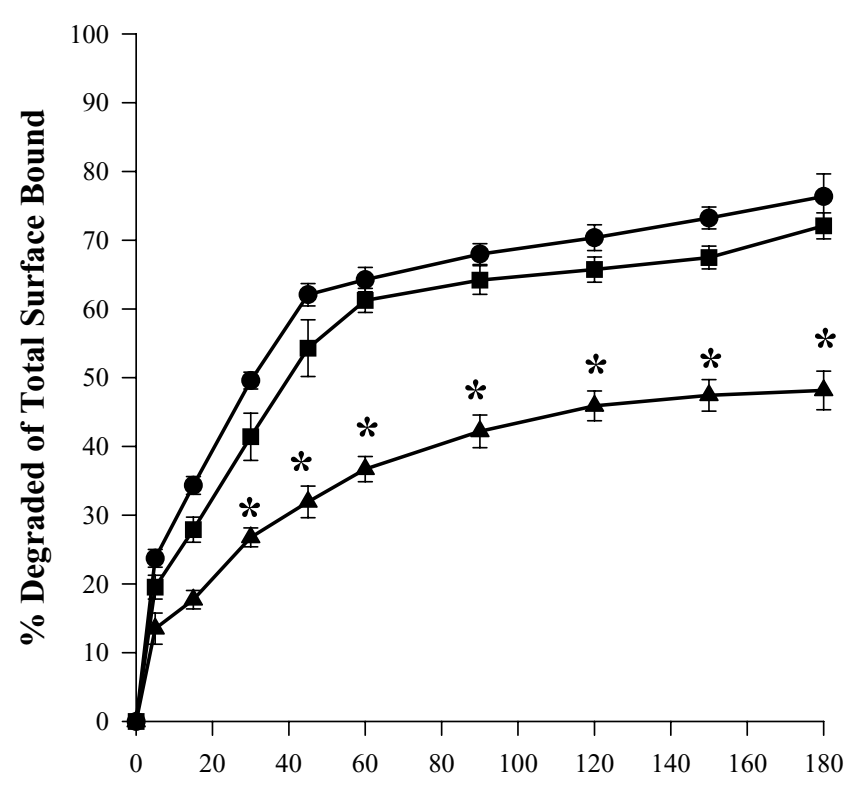

(B)

Time (minutes)

Fig. 6. (A, B) Internalization and degradation of cell surface-bound ${ }^{125}$ I-MAA-Alb by isolated LECs from chow-fed $(\boldsymbol{\square})$, pair-fed $(\mathbf{O})$, and ethanol-fed $(\boldsymbol{\Delta})$ rats. LEC suspensions $\left(1 \times 10^{6} \mathrm{cells} / \mathrm{mL}\right.$ in HBSS medium) were allowed to bind to ${ }^{125} \mathrm{I}-\mathrm{MAA}-\mathrm{Alb}$ at $4^{\circ}$ as described in Section 2 . The degradation rate of cell surface-bound ligand was determined at various time points following treatment with HBSS medium at pH 3.0 (A). Additionally, the rate of degradation of the labeled ligand was determined as described in Section 2 (B). Each point is the mean \pm SD of 8 experiments. Both the amount of cell surface-bound ligand (A) and rates of degradation (B) are expressed as percent of the initial amount of surface-bound ligand. Values significantly different from controls are indicated at ${ }^{*} P<0.05$.

LECs, their physiological relevance in disease processes has been questioned with respect to the extent the protein is modified, and the source of the formaldehyde. In contrast, acetaldehyde adducts that could form following chronic ethanol consumption are physiologically relevant, but do

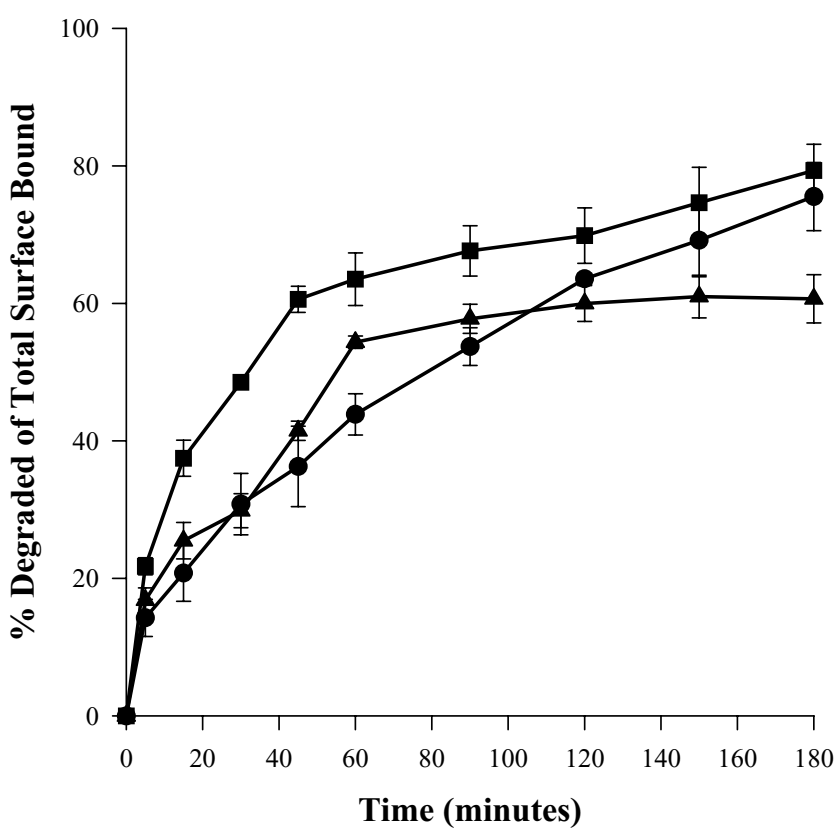

Fig. 7. Degradation of cell-associated ${ }^{125}$ I-MAA-Alb by LECs isolated from chow-fed $(\boldsymbol{\square})$, pair-fed $(\boldsymbol{O})$, and ethanol-fed $(\boldsymbol{\Delta})$ rats. Experimental conditions were identical to those listed for Fig. 6. Rates of degradation of the internalized ligand were assessed as described in Section 2. Briefly, the rate of degradation is expressed as percent of the maximal amount of internalized ligand for each time point. Each point is the mean $\pm \mathrm{SD}$ of 8 experiments, and no significant differences $(P<0.05)$ were observed between ethanol and control cells at any of the time points tested.

not result in high levels of degradation (approximately $100 \mu \mathrm{g}$ or less) depending upon the level of modification [8]. Thus, the significance of impaired RME in LECs has been, to this point, lessened by the lack of a physiological relevant ligand (adduct).

In a report by Tuma et al. [5] it was shown that reacting MDA and AA with proteins results in a hybrid aldehydemodified protein adduct that has been designated MAA. This adduct is interesting as it forms at physiologically relevant levels, results in a very stable and highly modified proteins, and induces immune responses in the absence of adjuvants. The MAA adduct has many interesting characteristics that suggest it may be a good ligand for removal by LECs. Therefore, it was the purpose of these experiments to investigate how MAA-Alb is removed from the liver, and whether chronic alcohol consumption affects this process.

The process of a ligand binding to a specific receptor, internalizing, and then being degraded is commonly known as RME. Step 1 in this process is the specific binding of a modified protein to a receptor located on the surface of the cell. The scavenger receptor (SR) family of receptors is a good candidate for this as they bind a number of chemically modified polyanionic compounds. Additionally, studies by other investigators have indicated this family of receptors are involved in the removal of a number of modified proteins $[16,20]$. Step 2 in the process is the internalization of the modified protein, and transport 
through the cytoplasm in endosomes to the lysosomes. The last step is the degradation of the protein by proteolytic enzymes in the lysosome, followed by transportation of the degraded products out of the cell.

Previous studies by our laboratories have shown that $\mathrm{f}$ $\mathrm{Alb}$ and AA-Alb are degraded very efficiently by in situ perfused rat livers [5,6,8-12], and that chronic ethanol consumption impairs this process. Also in these studies, it was possible to show that the removal of KCs by gadolinium chloride did not alter the degradation of f-Alb or AA$\mathrm{Alb}$ in situ. Additional studies using isolated LECs or KCs, confirmed this observation and strongly suggest that LECs are the principle cell type in the liver capable of degrading these modified aldehydes.

In studies described in this manuscript, isolated LECs from chow-fed, pair-fed, and ethanol-fed rats were shown to bind MAA-Alb through receptor(s) present on the cell surface. Further analysis of the binding of MAA-Alb to LECs, demonstrated a small but significant decrease in the binding of this ligand to LECs from ethanol-fed rats when compared to both control groups. Since the binding was significantly lower, but not enough to account for the 50-60\% decrease in degradation that has been reported, it was felt that the internalization and/or degradation of MAA-Alb must also be altered by chronic ethanol consumption. Thus, experiments were performed using a single round of MAA-Alb binding to assess internalization and degradation. Results of these experiments indicated a decrease in the internalization of the surface bound ligand that is consistent with the reported 50-60\% decrease in degradation.

When the data were normalized for the amount of MAAAlb degraded that was actually internalized, results between the three groups became relatively equal. This equal amount of degradation indicated that once the protein was internalized, it was degraded. Thus, these studies demonstrated that ethanol affects RME of MAA-Alb primarily at the postinternalization step rather than during degradation.

In order to assure that the binding and degradation were a result of the MAA modification of the protein; AA-Alb and MDA-Alb were used as negative controls. In these studies, it was shown that proteins modified with these aldehydes at $1 \mathrm{mM}$ concentrations (levels that are used to form the MAA adduct) do not result in significant levels of lysine modification $(<1 \%)$ and are degraded very poorly (approximately $75 \mu \mathrm{g}$ ) when compared to MAA-modification $(35.6 \%)$ and degradation $(400-500 \mu \mathrm{g})$. Thus, these aldehydes individually do not modify proteins very well, and they are not efficiently recognized by the receptors on LECs. More importantly, the combination of these two aldehydes at the same concentration $(1 \mathrm{mM})$, can cause an increase in both the modification of the protein and its subsequent degradation. Since both of these aldehydes have been shown to be present during chronic ethanol consumption, it is reasonable to believe that the MAA adduct may have a physiologically relevant role in aldehydes.
One point that has been difficult to investigate is the specificity of the binding of MAA-modified proteins. Normally, specificity is determined by inhibition with $10 \times$ or $100 \times$ cold ligand. However, in these studies $100 \times$ MAA-Alb caused an alteration in the liver structure, which resulted in the leakage of the perfusate from the liver within a short period of time. This resulted in the loss of ligand in the liver making it impossible to calculate binding and degradation. With respect to isolated LECs, the cell viability decreased in the presence of $100 \times$ MAA-Alb. Analysis of supernatants has shown that there was an increase in the level of tumor necrosis factor alpha (TNF$\alpha$ ) into the medium following exposure to MAA-Alb (data not shown), which could explain the cellular damage. Based on this observation, it is enticing to speculate that impaired RME of MAA-Alb could result in the stimulation of LECs to release cytokines/chemokines and other inflammatory products. Studies are currently underway to better assess these observations

In summary, MAA-Alb is a physiologically relevant ligand that forms following chronic ethanol consumption and appears to primarily be bound, internalized, and degraded by LECs. Following chronic ethanol consumption the ability of these cells to degrade the MAA-modified proteins is decreased (50-60\%) as a result of a defect in both the binding and internalization processes. Regardless, these alterations in RME may lead to a series of events by which these products would be left in the circulation and could: (1) stimulate LECs to release cytokine/chemokine; and/or, (2) circulate back to lymph nodes and/or the spleen to induce immune responses as has been previously reported. In either case, MAA-modified proteins may induce abnormal responses that could play significant roles in the development and/or progression of alcoholic liver disease.

\section{Acknowledgments}

This work was supported by National Institutes of Health Grants R29 AA10435, R01 AA07818 and R01 AA04961. Also supported by the Department of Veterans Affairs Alcohol Research Center. The authors thank the Experimental Immunology Laboratory, and the Liver Study Unit at the Omaha Veterans Affairs Medical Center, Carol A. Casey for technical help and supplying the antibody to the asialoglycoprotein receptor.

\section{References}

[1] Goldstein JL, Brown MS, Anderson RG, Russell DW, Schneider WJ. Receptor-mediated endocytosis: concepts emerging from the LDL receptor system. Annu Rev Cell Biol 1985;1:1-39.

[2] Wileman T, Harding C, Stahl P. Receptor-mediated endocytosis. Biochem J 1985;232(1):1-14.

[3] Smedsrod B, Pertoft H, Gustafson S, Laurent TC. Scavenger functions of the liver endothelial cell. Biochem J 1990;266(2):313-27. 
[4] Dalke DD, Sorrell MF, Casey CA, Tuma DJ. Chronic ethanol administration impairs receptor-mediated endocytosis of epidermal growth factor by rat hepatocytes. Hepatology 1990;12(5):1085-91.

[5] Tuma DJ, Thiele GM, Xu D, Klassen LW, Sorrell MF. Acetaldehyde and malondialdehyde react together to generate distinct protein adducts in the liver during long-term ethanol administration. Hepatology 1996;23(4):872-80.

[6] Hoek JB, Rubin E. Alcohol and membrane-associated signal transduction. Alcohol Alcohol 1990;25(2/3):143-56.

[7] Murakami M, Horiuchi S, Takata K, Morino Y. Scavenger receptor for malondialdehyde-modified high density lipoprotein on rat sinusoidal liver cells. Biochem Biophys Res Commun 1986;137(1):29-35.

[8] Thiele GM, Miller JA, Klassen LW, Tuma DJ. Long-term ethanol administration alters the degradation of acetaldehyde adducts by liver endothelial cells. Hepatology 1996;24(3):643-8.

[9] Thiele GM, Miller JA, Klassen LW, Tuma DJ. Chronic ethanol consumption impairs receptor-mediated endocytosis of formaldehyde-treated albumin by isolated rat liver endothelial cells. Hepatology 1999;29(5):1511-7.

[10] Xu D, Thiele GM, Beckenhauer JL, Klassen LW, Sorrell MF, Tuma DJ. Detection of circulating antibodies to malondialdehyde-acetaldehyde adducts in ethanol-fed rats. Gastroenterology 1998;115(3):686-92.

[11] Rolla R, Vay D, Mottaran E, Parodi M, Traverso N, Arico S, et al. Detection of circulating antibodies against malondialdehyde-acetaldehyde adducts in patients with alcohol-induced liver disease. Hepatology 2000;31(4):878-84.

[12] Lieber CS, DeCarli LM. The feeding of alcohol in liquid diets: two decades of applications and 1982 update. Alcohol Clin Exp Res 1982;6(4):523-31.

[13] Kikugawa K, Ido Y. Studies on peroxidized lipids. V. Formation and characterization of 1,4-dihydropyridine-3,5-dicarbaldehydes as model of fluorescent components in lipofusion. Lipids 1984;(19):600-8.

[14] McConahey PJ, Dixon FJ. Radioiodination of proteins by the use of the chloramine-T method. Methods Enzymol 1980;70(A):210-3.

[15] Mego JL, Bertini F, McQueen JD. The use of formaldehyde-treated 131-I-albumin in the study of digestive vacuoles and some properties of these particles from mouse liver. J Cell Biol 1967;32(3):699-707.
[16] Horiuchi S, Murakami M, Takata K, Morino Y. Scavenger receptor for aldehyde-modified proteins. J Biol Chem 1986;261(11):4962-6.

[17] Rees GM, Miller JA, Casey CA, Tuma DJ. Chronic ethanol administration impairs degradation of formaldehyde-treated albumin by the perfused rat liver. Alcohol Clin Exp Res 1993;17(6):1309-12.

[18] Lowry OH, Rosebrough NJ, Farr AL, Randall RJ. Protein measurement with the Folin phenol reagent. J Biol Chem 1951;193:26575.

[19] Braet F, De Zanger R, Sasaoki T, Baekeland M, Janssens P, Smedsrod $B$, et al. Assessment of a method of isolation, purification, and cultivation of rat liver sinusoidal endothelial cells. Lab Invest 1994; 70(6):944-52.

[20] Haberland ME, Fogelman AM. Scavenger receptor-mediated recognition of maleyl bovine plasma albumin and the demaleylated protein in human monocyte macrophages. Proc Natl Acad Sci USA 1985;82(9): 2693-7.

[21] Habeeb AF. Determination of free amino groups in proteins by trinitrobenezenesulfonic acid. Anal Biochem 1966;14:328-36.

[22] Nilsson M, Berg T. Uptake and degradation of formaldehyde-treated ${ }^{125}$ I-labelled human serum albumin in rat liver cells in vivo and in vitro. Bichim Biophys Acta 1977;497(1):171-82.

[23] Weigel PH, Oka JA. Endocytosis and degradation mediated by the asialoglycoprotein receptor in isolated rat hepatocytes. J Biol Chem 1982;257:1201-7.

[24] Horiuchi S, Takata K, Morino Y. Characterization of a membraneassociated receptor from rat sinusoidal liver cells that binds formaldehyde-treated serum albumin. J Biol Chem 1985;260:475-81.

[25] Eskild W, Kindberg GM, Smedsrod B, Blomhoff R, Norum KR, Berg T. Intracellular transport of formaldehyde-treated serum albumin in liver endothelial cells after uptake via scavenger receptors. Biochem J 1989;258:511-20.

[26] Blomhoff R, Eskild W, Berg T. Endocytosis of formaldehyde-treated serum albumin via scavenger pathway in liver endothelial cells. Biochem J 1984;218:81-6.

[27] Horiuchi S, Takata K, Morino Y. Purification of a receptor for formaldehyde-treated serum albumin from rat liver. J Biol Chem 1985;260:482-8. 